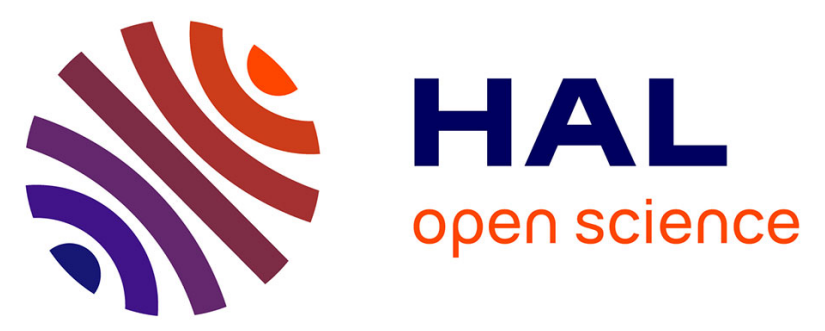

\title{
Backstepping Approach for Autonomous Mobile Robot Trajectory Tracking
}

\author{
Benaoumeur Ibari, Laredj Benchikh, Amar Reda Hanifi Elhachimi, Zoubir
}

Ahmed-Foitih

\section{To cite this version:}

Benaoumeur Ibari, Laredj Benchikh, Amar Reda Hanifi Elhachimi, Zoubir Ahmed-Foitih. Backstepping Approach for Autonomous Mobile Robot Trajectory Tracking. Indonesian Journal of Electrical Engineering and Computer Science, 2016, 2 (3), pp.478-485. 10.11591/ijeecs.v2.i3.pp478-485 . hal01328410

\section{HAL Id: hal-01328410 https://hal.science/hal-01328410}

Submitted on 7 Jun 2016

HAL is a multi-disciplinary open access archive for the deposit and dissemination of scientific research documents, whether they are published or not. The documents may come from teaching and research institutions in France or abroad, or from public or private research centers.
L'archive ouverte pluridisciplinaire HAL, est destinée au dépôt et à la diffusion de documents scientifiques de niveau recherche, publiés ou non, émanant des établissements d'enseignement et de recherche français ou étrangers, des laboratoires publics ou privés. 


\title{
Backstepping Approach for Autonomous Mobile Robot Trajectory Tracking
}

\author{
Ibari Benaoumeur ${ }^{\star 1}$, Benchikh Laredj ${ }^{2}$, Hanifi Elhachimi Amar Reda ${ }^{3}$, and Ahmed-foitih \\ Zoubir $^{4}$ \\ ${ }^{1,3,4}$ Laboratory of Power Systems, Solar Energy and Automation L.E.P.E.S.A. University of Sciences and \\ Technology of Oran USTO/MB. Oran, Algeria \\ ${ }^{2}$ IBISC laboratory (Informatics, Integrative Biology and Complex Systems), University of Evry, France \\ "Corresponding author, e-mail: benaoumeur.ibari@univ-usto.dz
}

\begin{abstract}
This paper proposes a backstepping controller design for trajectory tracking of unicycle-type mobile robots. The main object of the control algorithms developed is to design a robust output tracking controller. The design of the controller is based on the lyapunov theorem, kinematic tracking controller of an unicyclelike mobile robot is used to provides the desired values of the linear and angular velocities for the given trajectory. A Lyapunov-based stability analysis is presented to guarantee the robot stability of the tracking errors. Simulation and experimental results show the effectiveness of the proposed robust controller in term of accuracy and stability under different load conditions.
\end{abstract}

Keywords: Non-linear systems, Trajectory tracking, Dynamic model, backstepping.

\section{Introduction}

Differential wheeled robot are becoming more popular for performing tasks that are too dangerous or tedious for humans, they are widely used in: industry, science, education, entertainment and military applications [1], for this way, There are many research articles emphasizing the importance of designing controller at the control of mobile robot. Most of them have focused on trajectory traking $[2,3,4]$. In these algorithms, the velocity control inputs is defined to stabilize the closed-loop system. In path following, the velocity control is designed to stabilize a car-like mobile robot [5], this problem of stabilization is solved about a desired posture in [6].

Most controllers designed in control systems are not based on dynamic systems and control theory [7, 8, 9]. In [10] an adaptive following controller based on the PID for mobile robot path following is presented, one advantage of their controller is that its the control law is constructed on the basis of Lyapunov stability theory. Once more, just a model of the robot mobile kinematics is used and no experimental results were reported. However, it is necessary to using the tools from control theory and dynamic systems in order to ensure system stability.

Many researchers have shown interest in applying controllers designed for wheeled robot mobile based on dynamic model. Different approaches have been investigated using fuzzy control $[11,12]$, sliding mode control (SMC)[13, 14], adaptive control [15, 16, 17], or backstepping control $[18,19]$.

In the presence of parametric uncertainties and noises in only its dynamic model, a combination of model reference adaptive control and gain scheduling is developed in [15] to control the robot motion by the adaptive controller. In [16] an adaptive controller based on the dynamic model provides the torques of the robot actuators for yielding the required velocities is designed in the presence of unknown dynamics only in its dynamic model. An adaptive trajectory-tracking controller based on the robot dynamics is proposed with experimental results in [17], and its stability is proved using the Lyapunov stability theorem, The dynamic controller is capable of updating the estimated parameters, which are directly related to physical parameters of the robot. In order to overcome trajectory tracking problems, in [20] an adaptive nonlinear control of a wheeled mobile 
robot approach is proposed in the presence of uncertainties. A methodology based on linear interpolation is used in [21] to design control algorithms for trajectory tracking of mobile robots, The proposed control can be applied to the design of a large class a mobile robot.

In this paper, the trajectory tracking problem for an unicycle-like mobile robot has been addressed. First, the dynamic model of the unicycle-like mobile is presented and the kinematic controller, which is based on the robot kinematics, is introduced to generate the desired linear and angular velocities for the given trajectory. The control law is developed using backstepping technique to generate the commands of linear and angular velocities delivered to the robot servos , and its stability property is proved using the Lyapunov theory.

The rest of the paper is organized as follows. Section 2 presents the dynamic unicycle-like robot model. The kinematic controller is detailed and the complete equations of the backstepping controller design are developed in section 3. Respectively, in section 4, simulations and experimental results are discussed. Finally, section 5 concludes this paper.

\section{Dynamic model}

In this work, the dynamic model of the unicycle-like mobile is considered, this model is proposed in [22], The mobile robot is illustrated in Figure 1. $G$ is the center of mass of the robot, $C$ is the position of the castor wheel, $E$ is the location of a tool onboard the robot, $\mathrm{h}$ is the point of interest with coordinates $\mathrm{x}$ and $\mathrm{y}$ in the $\mathrm{XY}$ plane, $\psi$ is the robot orientation, and $a$ is the distance between the point of interest and the central point of the virtual axis linking the traction wheels (point $B$ ), $u$ and $\omega$ are the linear and angular velocities of the robot.

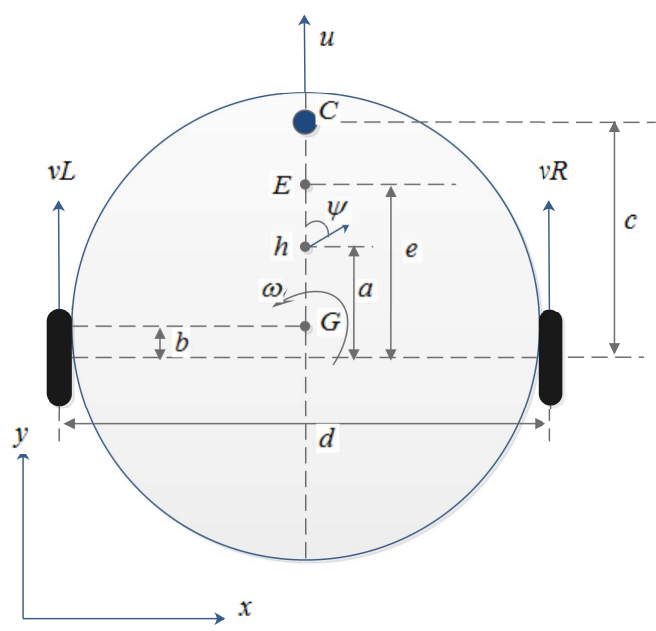

Figure 1. The unicycle-like mobile robot.

The model of the mobile robot can be obtained as follows [22]:

$$
\left(\begin{array}{c}
\dot{x} \\
\dot{y} \\
\dot{\psi} \\
\dot{u} \\
\dot{\omega}
\end{array}\right)=\left(\begin{array}{c}
u \cos (\psi)-a w \sin (\psi) \\
u \sin (\psi)+a w \cos (\psi) \\
\omega \\
\frac{\lambda_{3}}{\lambda_{1}} \omega^{2}-\frac{\lambda_{4}}{\lambda_{1}} u \\
-\frac{\lambda_{5}}{\lambda_{2}} u \omega-\frac{\lambda_{6}}{\lambda_{2}} \omega
\end{array}\right)+\left(\begin{array}{cc}
0 & 0 \\
0 & 0 \\
0 & 0 \\
\frac{1}{\lambda_{1}} & 0 \\
0 & \frac{1}{\lambda_{2}}
\end{array}\right)\left(\begin{array}{l}
u_{r e f} \\
\omega_{r e f}
\end{array}\right)
$$

The parameters of the dynamic model are: $\lambda_{i}, i=1 \ldots, 6$ and defined as follows: 


$$
\left\{\begin{array}{c}
\lambda_{1}=\frac{\frac{R_{a}}{k_{a}}\left(m R_{t} r+2 I_{e}\right)+2 r k_{D T}}{\left(2 r k_{P T}\right)} \\
\lambda_{2}=\frac{\frac{R_{a}}{k_{a}}\left(I_{e} d^{2}+2 R_{t} r\left(I_{z}+m b^{2}\right)\right)+2 r d k_{D R}}{\left(2 r d k_{P R}\right)} \\
\lambda_{3}=\frac{R_{a}}{k_{k}} \frac{m b R_{t}}{2 k_{P T}} \\
\lambda_{4}=\frac{\frac{R_{a}}{k_{a}}\left(\frac{k_{a} k_{a}}{R_{a}}+B_{e}\right)}{\left(r k_{P T}\right)}+1 \\
\lambda_{5}=\frac{R_{a}}{k_{a}} \frac{m b R_{t}}{2 k_{P R}} \\
\lambda_{6}=\frac{\frac{R_{a}}{k_{a}}\left(\frac{k_{a} k_{a}}{R_{a}}+B_{e}\right) d}{\left(r k_{P R}\right)}+1
\end{array}\right.
$$

where $\mathrm{m}$ is the robot mass, $I_{z}$ is the robot moment of inertia at $\mathrm{G}, \mathrm{r}$ is the right and left wheel radius, $I_{e}$ and $B_{e}$ are the moment of inertia and the viscous friction coefficient of the combined motor rotor, gearbox, and wheel, and $R_{t}$ is the nominal radius of the tire, $k_{b}$ is electromotive constant of motors, $k_{a}$ is the constant of torque. $R_{a}$ is the electrical resistance of the motors, $\mathrm{b}$ and $\mathrm{d}$ are the distances.

The robot have PD controllers to control the velocities of each motor, with proportional gains $k_{P T}$ and $k_{P R}$, and derivative gains $k_{D T}$ and $k_{D R}$.

\section{Robust controller design}

In this work, two different types of controllers are considered : kinematic controller for external loop and a backstepping controller for an internal loop as see in figure 2.

\subsection{Kinematic controller}

For the given trajectory, the desired values of the linear and angular velocities are generated by the kinematic controller, it is based on the kinematic model of the robot.

The kinematic equations of mobile robot in Figure 1 are described by:

$$
\left(\begin{array}{l}
\dot{x} \\
\dot{y}
\end{array}\right)=A\left(\begin{array}{c}
u_{r e f} \\
\omega_{r e f}
\end{array}\right)
$$

with

$$
A=\left(\begin{array}{cc}
\cos (\psi) & -\operatorname{asin}(\psi) \\
\sin (\psi) & \operatorname{acos}(\psi)
\end{array}\right)
$$

whose respectively $u_{r e f}, \omega_{\text {ref }}$ are the desired values of the linear and angular velocities and $h(x, y)$ is the point of interest.

whose inverse is

$$
A^{-1}=\left(\begin{array}{cc}
\cos (\psi) & \sin (\psi) \\
-\frac{1}{a} \sin (\psi) & \frac{1}{a} \cos (\psi)
\end{array}\right)
$$

Thus, choosing the control law

$$
\left(\begin{array}{l}
u_{r e f}^{k} \\
\omega_{r e f}^{k}
\end{array}\right)=\left(\begin{array}{cc}
\cos \psi & \sin \psi \\
\frac{-1}{a} \sin \psi & \frac{1}{a} \cos \psi
\end{array}\right)\left(\begin{array}{l}
\dot{x}_{d}+\xi_{x} \\
\dot{y}_{d}+\xi_{y}
\end{array}\right)
$$

where $\xi_{x}=x_{d}-x, \xi_{y}=y_{d}-y$ are the current position errors, $h(x, y)$ and $h_{d}\left(x_{d}, y_{d}\right)$ are the current and the desired coordinates.

Now, consider the position error

$$
\left(\begin{array}{c}
\dot{\xi}_{x}+\xi_{x} \\
\dot{\xi_{y}}+\xi_{y}
\end{array}\right)=\left(\begin{array}{l}
0 \\
0
\end{array}\right)
$$

Thus, choosing the Lyapunov candidate function

$$
V_{\xi}=\frac{1}{2} \xi^{T} \xi \Rightarrow \dot{V}_{\xi}=\xi^{T} \dot{\xi}<0
$$


where $\xi=\left[\begin{array}{ll}\dot{\xi}_{x}+\xi_{x} & \dot{\xi}_{y}+\xi_{y}\end{array}\right]^{T}$, therefore, from (7) and (8) it results that:

$$
\dot{V}_{\xi}=\left\{\begin{array}{l}
\xi_{x}^{T} \dot{\xi}_{x}=-\xi_{x}^{T} \xi_{x}<0 \\
\xi_{y}^{T} \dot{\xi}_{y}=-\xi_{y}^{T} \xi_{y}<0
\end{array}\right.
$$

is negative definite.

Clearly, if $\xi$ goes to zero then $h$ converges to $h_{d}$ and the tracking error is asymptotically stable, which means that $\xi \longrightarrow 0$ as $t \longrightarrow \infty$ Therefore, (6) is a satisfactory tracking controller for system (3).

\subsection{Backstepping Controller design and stability analysis}

The controller receives from the kinematic controller the references for linear and angular velocities, and generates another pair of linear and angular velocities to be delivered to the robot servos, as shown in Figure 2.

The backstepping control is used to design the controller which is making the error dynamics

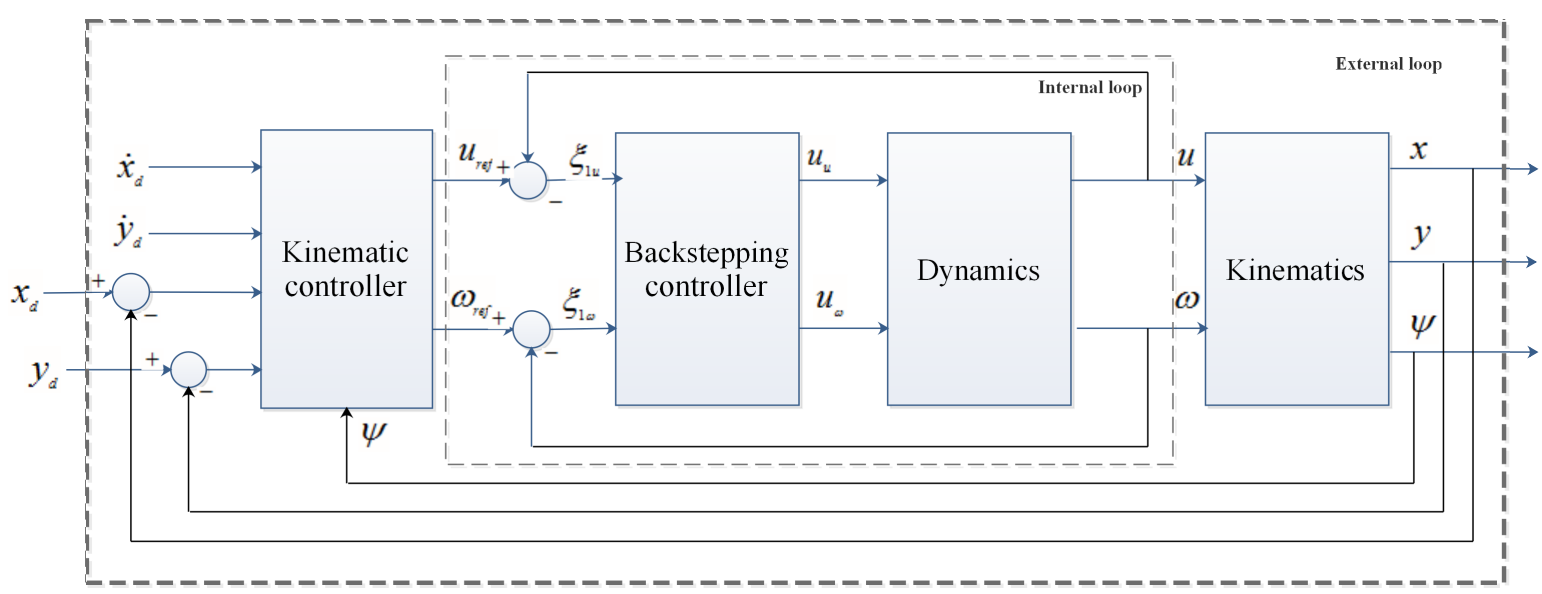

Figure 2. Control structure.

stable $[23,24]$. The design of the backstepping controller is based on the lyapunov theorem, the objective of this technique is to determine a control law that provides the system stability. The dynamic part of equation (1) is:

$$
\left\{\begin{array}{l}
\dot{u}=\frac{\lambda_{3}}{\lambda_{1}} \omega^{2}-\frac{\lambda_{4}}{\lambda_{1}} u+\frac{u_{r e f}}{\lambda_{1}} \\
\dot{\omega}=\frac{\lambda_{5}}{\lambda_{2}} u \omega-\frac{\lambda_{6}}{\lambda_{2}} \omega+\frac{\omega_{r e f}}{\lambda_{2}}
\end{array}\right.
$$

In the first step, the output error between the reference and actual controls is given by:

$$
\begin{gathered}
\xi_{1 u}=u_{r e f}-u \Longrightarrow \dot{\xi}_{1 u}=u_{r e f}-\dot{u} \\
\xi_{1 \omega}=\omega_{r e f}-\omega \Longrightarrow \dot{\xi}_{1 \omega}=\omega_{r e f}-\dot{\omega}
\end{gathered}
$$

Choose a Lyapunov functions candidate as

$$
V\left(\xi_{1 u}\right)=\frac{1}{2} \xi_{1 u}^{2}, V\left(\xi_{1 \omega}\right)=\frac{1}{2} \xi_{1 \omega}^{2}
$$

The time derivative of the Lyapunov candidate functions can be written as

$$
V\left(\dot{\xi}_{1 u}\right)=\xi_{1 u} \dot{\xi}_{1 u}, V\left(\dot{\xi}_{1 \omega}\right)=\xi_{1 \omega} \dot{\xi}_{1 \omega}
$$


The stability of the equilibrium at the origin of the errors system can be obtained by:

$$
\left\{\begin{array}{c}
\dot{u}_{r e f}-\dot{u}=-K_{1 u} \xi_{1 u} \\
\dot{\omega}_{r e f}-\dot{\omega}=-K_{1 \omega} \xi_{1 \omega}
\end{array}\right.
$$

where $K_{1 u}>0, K_{1 \omega}>0$ are design parameters. and a virtual controls law is defined by:

$$
\left\{\begin{array}{l}
u_{u^{\prime}}=\dot{u}_{r e f}+K_{1 u} \xi_{1 u} \\
u_{\omega^{\prime}}=\dot{\omega}_{r e f}+K_{1 \omega} \xi_{1 \omega}
\end{array}\right.
$$

From (14) and (15) it follows that

$$
\left\{\begin{array}{l}
V\left(\dot{\xi}_{1 u}\right)=-K_{1 u} \xi_{1 u}^{2}<0 \\
V\left(\dot{\xi}_{1 \omega}\right)=-K_{1 \omega} \xi_{1 \omega}^{2}<0
\end{array}\right.
$$

At the second step the new errors given by:

$$
\left\{\begin{array}{l}
\xi_{2 u}=\dot{u}-u_{u^{\prime}} \Longrightarrow \dot{\xi}_{2 u}=\ddot{u}-\dot{u}_{u^{\prime}} \\
\xi_{2 \omega}=\dot{\omega}-u_{\omega^{\prime}} \Longrightarrow \dot{\xi}_{2 \omega}=\ddot{\omega}-\dot{u}_{\omega^{\prime}}
\end{array}\right.
$$

From (16) and (18) it follows that:

$$
\left\{\begin{array}{l}
\dot{\xi_{2 u}}=\ddot{u}-\ddot{u}_{r e f}-K_{1 u} \dot{\xi}_{1 u} \\
\dot{\xi_{2 \omega}}=\ddot{\omega}-\ddot{\omega}_{r e f}-K_{1 \omega} \dot{\xi}_{1 \omega}
\end{array}\right.
$$

The augmented Lyapunov functions are given by:

$$
\left\{\begin{array}{l}
V\left(\xi_{1 u}, \xi_{2 u}\right)=\frac{\left(\xi_{1 u}^{2}+\xi_{2 u}^{2}\right)}{2} \\
V\left(\xi_{1 \omega}, \xi_{2 \omega}\right)=\frac{\left(\xi_{1 \omega}^{2}+\xi_{2 \omega}^{2}\right)}{2}
\end{array}\right.
$$

Its time derivative is then:

$$
\left\{\begin{array}{l}
\dot{V}\left(\xi_{1 u}, \xi_{2 u}\right)=\xi_{1 u} \dot{\xi}_{1 u}+\xi_{2 u} \dot{\xi}_{2 u} \\
\dot{V}\left(\xi_{1 \omega}, \xi_{2 \omega}\right)=\xi_{1 \omega} \dot{\xi}_{1 \omega}+\xi_{2 \omega} \dot{\xi}_{2 \omega}
\end{array}\right.
$$

Now, after substituting (11),(12) and (18) in (21) it results that:

$$
\left\{\begin{array}{c}
\dot{V}\left(\xi_{1 u}, \xi_{2 u}\right)=-\xi_{1 u} \xi_{2 u}-K_{1 u} \xi_{1 u}^{2}+\xi_{2 u}\left(\ddot{u}-\ddot{u}_{r e f}-K_{1 u}\left(-K_{1 u} \xi_{1 u}-\xi_{2 u}\right)\right) \\
\dot{V}\left(\xi_{1 \omega}, \xi_{2 \omega}\right)=-\xi_{1 \omega} \xi_{2 \omega}-K_{1 \omega} \xi_{1 \omega}^{2}+\xi_{2 \omega}\left(\ddot{\omega}-\ddot{\omega}_{r e f}-K_{1 \omega}\left(-K_{1 \omega} \xi_{1 \omega}-\xi_{2 \omega}\right)\right)
\end{array}\right.
$$

In order to satisfy the Lyapunov Condition $\dot{V}\left(\xi_{1 u}, \xi_{2 u}\right)<0$ and $\dot{V}\left(\xi_{1 \omega}, \xi_{2 \omega}\right)<0$, the controls law is defined by :

$$
\left\{\begin{array}{c}
u_{u}=\lambda_{1}\left(\ddot{u}_{r e f}-\left(K_{1 u}+K_{2 u}\right) \xi_{2 u}-\left(1-K_{1 u}^{2}\right) \xi_{1 u}\right)-2 \lambda_{3} \omega \dot{\omega}+\lambda_{4} \dot{u} \\
u_{\omega}=\lambda_{2}\left(\ddot{\omega}_{r e f}-\left(K_{1 \omega}+K_{2 \omega}\right) \xi_{2 \omega}-\left(1-K_{1 \omega}^{2}\right) \xi_{1 \omega}\right)+\lambda_{5}(\dot{u} \omega+u \dot{\omega})+\lambda_{6} \dot{\omega}
\end{array}\right.
$$

In such a way that:

$$
\left\{\begin{array}{c}
\dot{V}\left(\xi_{1 u}, \xi_{2 u}\right)=-K_{1 u} \xi_{1 u}^{2}-K_{2 u} \xi_{2 u}^{2}<0 \\
\dot{V}\left(\xi_{1 \omega}, \xi_{2 \omega}\right)=-K_{1 \omega} \xi_{1 \omega}^{2}-K_{2 \omega} \xi_{2 \omega}^{2}<0
\end{array}\right.
$$

$V$ along the trajectories is negative definite. This proves the asymptotic stability of the racking trajectory of the wheeled mobile robot, which allows verifying the stability of the equilibrium at the origin of the error system. 


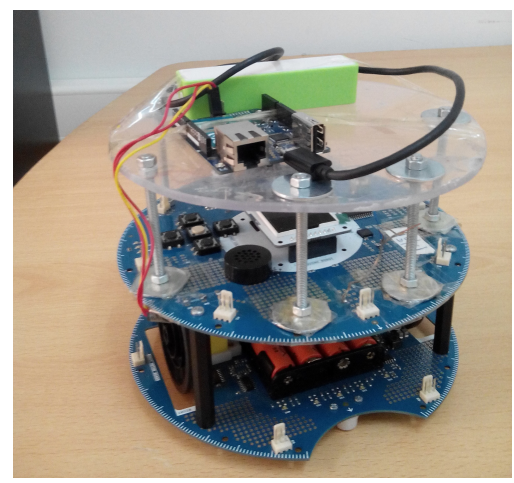

Figure 3. Arduino robot mobile.

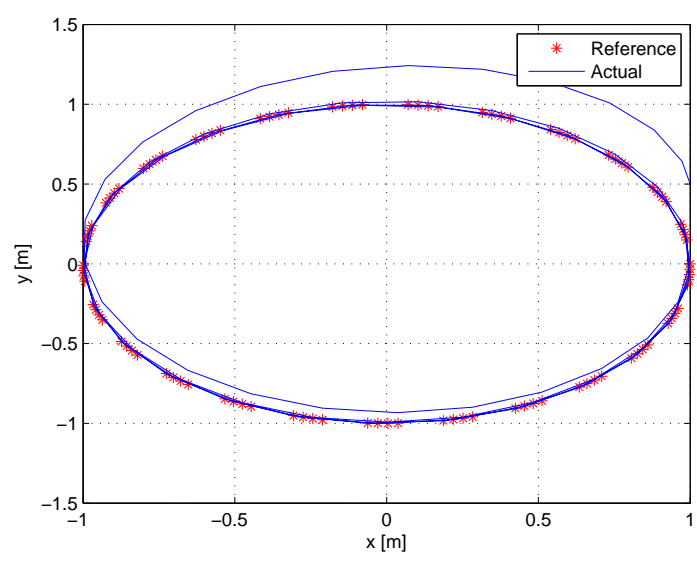

(a) Robot Trajectory

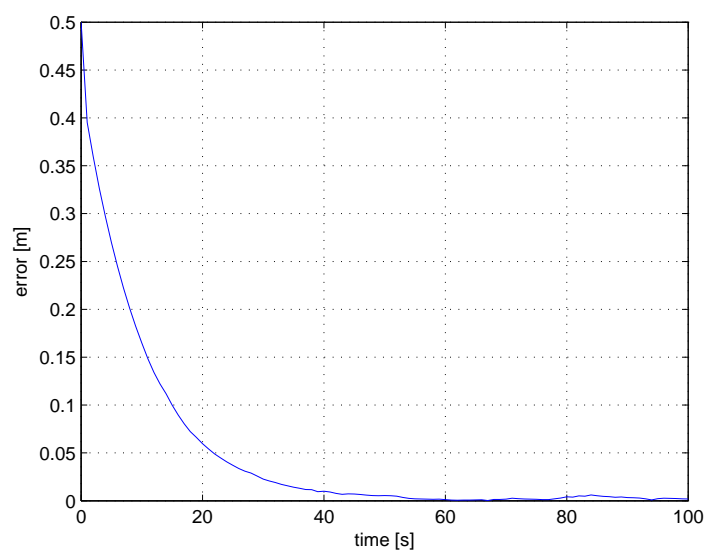

(c) Distance errors for experiments.
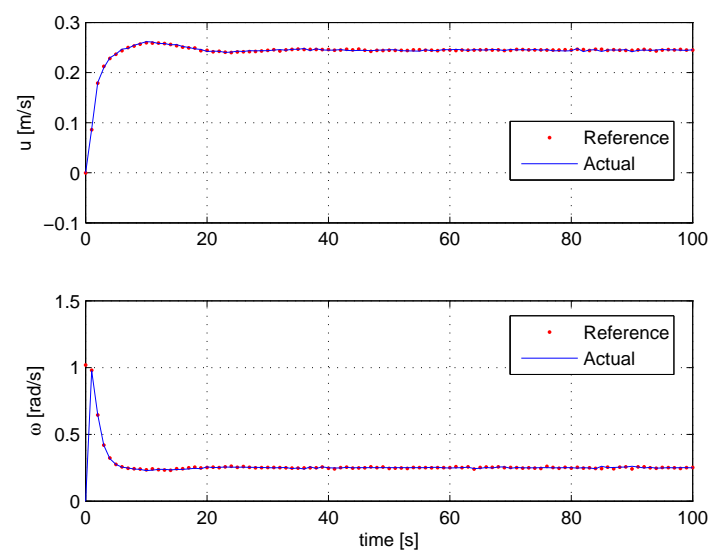

(b) The Linear Velocity and Angular Velocity.
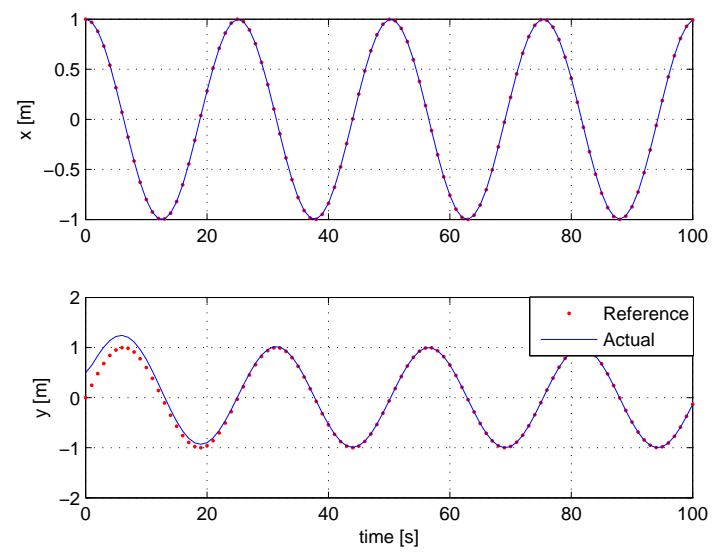

(d) Time evolution of current and the desired coordinates. .

Figure 4. Experimental results

\section{Result and Analysis}

In this section, experiments and simulations were carried out at Laboratory of Power Systems, Solar Energy and Automation L.E.P.E.S.A, University of sciences and technology of Oran, 
Oran, Algeria. The proposed backstepping controller is tested on a Arduino Robot Mobile (Radius of $185 \mathrm{~mm}$, height of $85 \mathrm{~mm}$ and weight of $0.150 \mathrm{~kg}$ ), see Figure 3, Arduino Robot has two processors based on the ATmega32u4, which admits linear and angular velocities as input reference signals and it uses two DC motor driven wheels. The robot is wirelessly connected to computer with Arduino Yun, these modules can communicate point to point, from one point to a PC, or in a mesh network. Card arduino Yun mounted on the robot that is used to transmit data from matlab to the robot using the Wireless network protocol.

\subsection{Discussion}

Experimental results for the backstepping controller proposed in section 3 are shown in figure 4. The task for a mobile robot is to follow a circular trajectory, the mobile robot starts from the initial posture $P_{0}(x, y, \theta)=\left(1,0.5,0^{\circ}\right)$, it can be seen that the robot follows the reference trajectory with small error as see in figure $4 \mathrm{a}$. At $\mathrm{t}=20 \mathrm{~s}$, it can be seen in figure $4 \mathrm{c}$ that the distance error begins to increase with time, and tends to zero. The robot velocities $v$ and $\omega$ are plotted in Figure $4 \mathrm{~b}$, and asymptotically tracks their desired reference, there are used to obtain the right and left velociities $\left(\omega_{l}, \omega_{r}\right)$. From Figure $4 \mathrm{~d}$, it can be seen that robot arrives at the end of the reference trajectory and catches up to the desired coordinates.

Unlike the aforementioned works, especially in comparison with [17, 20], in this method, the tracking errors are very low and the system is guaranteed to be stable.

\section{Conclusion}

In this work, a review of the kinematics and dynamics of a dierential drive wheeled mobile robot was given and a backstepping controller for a unicycle-like mobile robot was also studied and tested. The control law was created by giving the robot forward and angular reference velocities, collecting the actual velocities. The stability analysis based on Lyapunov theory shows the effectiveness of the control law which are the trajectory tracking and the stability maintaining of the closed loop dynamics of the mobile robot. The analysis of results shows the good performance of the proposed controller for trajectory tracking when applied to an experimental mobile robot in term of accuracy, stability and convergence. The tracking errors are very low with respect to the mobile robot dimensions. The proposed controller allowed for use on different robotic platforms and it can be tested in an environment with obstacles.

In future work, we intend to improve the mobile robot by using the augmented reality [25], This work can be applied also to remote control using the virtual reality [26].

\section{References}

[1] T. Lozano-Perez, I. J. Cox, and G. T. Wilfong, Autonomous robot vehicles. Springer Science \& Business Media, 2012.

[2] P. Antonini, G. Ippoliti, and S. Longhi, "Learning control of mobile robots using a multiprocessor system," Control Engineering Practice, vol. 14, no. 11, pp. 1279-1295, 2006.

[3] M. Corradini and G. Orlando, "Control of mobile robots with uncertainties in the dynamical model: a discrete time sliding mode approach with experimental results," Control Engineering Practice, vol. 10, no. 1, pp. 23-34, 2002.

[4] X. Feng, S. Velinsky et al., "Development of a distributed multiple mobile robot control system for automatic highway maintenance and construction," in Circuits and Systems, 1997. Proceedings of the 40th Midwest Symposium on, vol. 1. IEEE, 1997, pp. 489-492.

[5] C. C. De Wit, H. Khennouf, C. Samson, and O. J. Sordalen, "Nonlinear control design for mobile robots," Recent trends in mobile robots, vol. 11, pp. 121-156, 1993.

[6] C. Samson, "Time-varying feedback stabilization of car-like wheeled mobile robots," The International journal of robotics research, vol. 12, no. 1, pp. 55-64, 1993.

[7] R. Carelli and E. O. Freire, "Corridor navigation and wall-following stable control for sonarbased mobile robots," Robotics and Autonomous Systems, vol. 45, no. 3, pp. 235-247, 2003. 
[8] F. Künhe, J. Gomes, and W. Fetter, "Mobile robot trajectory tracking using model predictive control," in II IEEE latin-american robotics symposium, 2005.

[9] W. W. H. C. Y. Wang and P. Woo, "Adaptive exponential stabilization of mobile robots with uncertainties," 1999.

[10] T.-S. Jin and H.-H. Tack, "Path following control of mobile robot using lyapunov techniques and pid cntroller," International Journal of Fuzzy Logic and Intelligent Systems, vol. 11, no. 1, pp. 49-53, 2011.

[11] T. Das and I. N. Kar, "Design and implementation of an adaptive fuzzy logic-based controller for wheeled mobile robots," Control Systems Technology, IEEE Transactions on, vol. 14, no. 3, pp. 501-510, 2006.

[12] Y. Cai, Q. Zhan, and X. Xi, "Path tracking control of a spherical mobile robot," Mechanism and Machine Theory, vol. 51, pp. 58-73, 2012.

[13] G. Guoqin, R. Yi, Z. Haiyan, and F. Zhiming, "Smooth sliding mode control for trajectory tracking of greenhouse spraying mobile robot," TELKOMNIKA Indonesian Journal of Electrical Engineering, vol. 11, no. 2, pp. 642-652, 2013.

[14] L. Gracia, F. Garelli, and A. Sala, "Integrated sliding-mode algorithms in robot tracking applications," Robotics and Computer-Integrated Manufacturing, vol. 29, no. 1, pp. 53-62, 2013.

[15] M. Ashoorirad, R. Barzamini, A. Afshar, and J. Jouzdani, "Model reference adaptive path following for wheeled mobile robots," in Information and Automation, 2006. ICIA 2006. International Conference on. IEEE, 2006, pp. 289-294.

[16] E. Canigur and M. Ozkan, "Model reference adaptive control of a nonholonomic wheeled mobile robot for trajectory tracking," in Innovations in Intelligent Systems and Applications (INISTA), 2012 International Symposium on. IEEE, 2012, pp. 1-5.

[17] F. N. Martins, W. C. Celeste, R. Carelli, M. Sarcinelli-Filho, and T. F. Bastos-Filho, "An adaptive dynamic controller for autonomous mobile robot trajectory tracking," Control Engineering Practice, vol. 16, no. 11, pp. 1354-1363, 2008.

[18] R. Fierro and F. L. Lewis, "Control of a nonholonomic mobile robot: backstepping kinematics into dynamics," in Decision and Control, 1995., Proceedings of the 34th IEEE Conference on, vol. 4. IEEE, 1995, pp. 3805-3810.

[19] G. Yanfeng, Z. Hua, and Y. Yanhui, "Back-stepping and neural network control of a mobile robot for curved weld seam tracking," Procedia Engineering, vol. 15, pp. 38-44, 2011.

[20] J. Taheri-Kalani and M. Khosrowjerdi, "Adaptive trajectory tracking control of wheeled mobile robots with disturbance observer," International Journal of Adaptive Control and Signal Processing, vol. 28, no. 1, pp. 14-27, 2014.

[21] G. Scaglia, A. Rosales, L. Quintero, V. Mut, and R. Agarwal, "A linear-interpolation-based controller design for trajectory tracking of mobile robots," Control Engineering Practice, vol. 18, no. 3, pp. 318-329, 2010.

[22] C. De La Cruz and R. Carelli, "Dynamic modeling and centralized formation control of mobile robots," in IEEE Industrial Electronics, IECON 2006-32nd Annual Conference on. IEEE, 2006, pp. 3880-3885.

[23] W. Y. Qiao, "Backstepping adaptive fuzzy scheme for scara grb400 robot," TELKOMNIKA Indonesian Journal of Electrical Engineering, vol. 11, no. 8, pp. 4229-4237, 2013.

[24] L. Chrif, Z. M. Kada, T. Mohamed, and N. Bastaoui, "Flight-path tracking control of an aircraft using backstepping controller," TELKOMNIKA Indonesian Journal of Electrical Engineering, vol. 15, no. 2, 2015.

[25] B. Ibari, K. Bouzgou, Z. Ahmed-Foitih, and L. Benchikh, "An application of augmented reality (ar) in the manipulation of fanuc 200ic robot," in Innovative Computing Technology (INTECH), 2015 Fifth International Conference on. IEEE, 2015, pp. 56-60.

[26] B. Ibari, Z. Ahmed-Foitih, and H. E. A. Reda, "Remote control of mobile robot using the virtual reality," International Journal of Electrical and Computer Engineering, vol. 5, no. 5, 2015. 